\title{
Services for spinal cord injured: availability and satisfaction
}

\author{
MWM Post ${ }^{1}$, FWA van Asbeck ${ }^{2}$, AJ van Dijk ${ }^{3}$ and AJP Schrijvers ${ }^{1}$ \\ ${ }^{1}$ Utrecht University, Department of Medicine; ${ }^{2}$ Rehabilitation Centre De Hoogstraat, Utrecht and ${ }^{3}$ Rehabilitation \\ Centre Het Roessingh, Enschede, The Netherlands
}

\begin{abstract}
This article discusses service delivery for Spinal Cord Injured (SCI) in the Netherlands. In this wealthy country, almost everyone has access to domestic adaptations and other equipment, regardless of income and with low, or without user contributions. However, satisfaction with this system or its products is rarely examined. Subjects in this research are 318 SCI individuals between 18 and 65 years of age, living in the community at a mean time of 3.6 years after injury. Availability of accessible housing, domestic adaptations, wheelchairs and outdoor transportation is investigated. Satisfaction with available services and satisfaction with service delivery procedures is measured by self-developed questionnaires. Relationships between these satisfaction scores and measures for functional health status (SIP68) and life satisfaction (LSQ) are analyzed. The presence of domestic adaptations is high, and $78.3 \%$ said their houses were sufficiently adapted at the time of the interview. Wheelchairs were generally available and most respondents had more than one. However, many users had complaints about their wheelchairs: $35.9 \%$ about their manual wheelchairs and $47.5 \%$ about their electric wheelchairs. Public transport was rarely used, $51.1 \%$ of respondents had an adapted car. Having an adapted car was significantly related to the ability to drive independently. Satisfaction with available services was acceptable, but satisfaction with service delivery procedures was very low. Satisfaction with available services did have a significant relationship with functional health status when the influence of the type of injury was taken into account. Satisfaction with available services also had a significant relationship with life satisfaction, after the influence of functional health status was taken into account. Further research on this topic is recommended.
\end{abstract}

Keywords: service delivery; consumer satisfaction; spinal cord injuries; functional health status; health services research

\section{Introduction}

Spinal cord injury (SCI) is often a seriously disabling condition. Persons with a SCI often remain dependent on services like wheelchairs, adapted cars and domestic adaptations for the rest of their lives., $1,2,3$ However, the relatively scarce research on this topic notes several problems. Tate et $a l^{4}$ show that work/ school outcomes are associated with the amount of transportation benefits and type of payor (catastrophic, Medicaid, private). In the Netherlands, Van Asbeck $^{5,6}$ noted problems with domestic adaptations, wheelchairs and equipment needed for resuming work, household or sports. Harrison ${ }^{7}$ questioned 62 spinal cord injured in Michigan (USA) and concluded that $25 \%$ did not have all services prescribed during rehabilitation, $46 \%$ did not have full access to their houses, and $73 \%$ indicated they were dependent on others to provide transportation to travel away from home. Nelson ${ }^{8}$ showed that out of SCI veterans who

Correspondence: MWM Post, M.Sc. used bowel care/shower chairs at home, over $66 \%$ felt their safety was compromised by their use. In England, Whiteneck et $a l^{9}$ reported that $40 \%$ out of 282 spinal cord injured needed changes in their adaptive equipment. Shirado et $a l^{10}$ mailed a survey to wheelchair bound SCI-patients in Japan about difficulties during winter outdoor activities, and found that there were many problems in using wheelchairs. Finally, Brooks ${ }^{11}$ reported a general user satisfaction with devices in a large sample of scientists and engineers with several kinds of disabilities, but, even in this sample, about $40 \%$ said using assistive devices is always or often restricting and frustrating.

Consumer satisfaction with service delivery procedures has, as far as we know, never been a subject of scientific research.

In this paper the delivery of domestic adaptations, wheelchairs and outdoor transportation facilities for spinal cord injured in the Netherlands are investigated. First, we will introduce relevant characteristics of the Dutch service delivery system. 


\section{Dutch service delivery system}

In the Netherlands, a comprehensive but also complex system exists for the provision of adaptations and technical aids. This research covers the period before April 1994, since then new legislation has been implemented, and that is a subject of evaluation research now. Before April 1994, the service delivery system was divided over the health care system, the social security system, the housing and the general financial support system. ${ }^{12,13}$

All inhabitants had access to domestic adaptations by the Regulation for the Adaptation of Private Homes (RGSHG) that is executed through the local communities. The national government's ascent is required for total costs exceeding 45,000 Dutch guilders. A user contribution of 500 Dutch guilders was required. Assessments of medical neccessity were made by the Joint Medical Service (GMD), which was an advisory unit in which medical advisers, vocational rehabilitation experts and legal assessors cooperate. Because it is expensive to adapt a house, the disabled person may have to move to a house that can be adapted more easily and therefore at a lower cost. When an adaptation or piece of equipment was denied, it was mostly because the GMD did not see any medical reason for it, or because the adaptation needed was commonly used in the population (for example: central heating will not be granted, because most houses have central heating). A medically assessed adaptation is only rarely denied by the payor.

Access to adaptive equipment like wheelchairs and other modes of transportation was regulated for every inhabitant between 18 and 65 years by the General Disablement Benefits Act (AAW). No user contribution was required and services were provided on loan. This act was implemented through the Industrial Insurance Boards (Bedrijfsverenigingen), assessments were usually also made by the Joint Medical Service (GMD). An adapted car was only assessed in case of necessity for transport to a workplace. For those who do not have a paying job, and have incomes below a certain level, adaptations of their own car (if present) are refunded. Others have no access to this type of service.

Finally, the General Act for Exceptional Medical Expenses (AWBZ) covered, amongst others, costs of stay in a rehabilitation centre and a limited list of technical aids like orthoses, aids for incontinence and home care technology. The AWBZ was also accessible to all inhabitants. Our respondents were assessed by the rehabilitation doctor or the occupational therapist. In short, every inhabitant between 18 and 65 years of age had access to all necessary services, irrespective of income and age. However, total budgets for the provision of individual technical aids were fixed, and the target groups were growing, so that a tendency towards rigid assessment rules existed.

The total market contained about 13,000 different pieces of equipment, made by 180 producers and sold by 900 suppliers and importers. The total turnover is about 850 million guilders (US\$ 550 Million) a year. ${ }^{14}$

\section{Methods}

\section{Population}

For this study persons with a SCI who were between 18 and 65 years of age, initially rehabilitated after injury in a specialized rehabilitation centre between 1986 and 1992, and who were living in the community at the time of research, were asked to participate. Persons were excluded when they did not live in The Netherlands any more or did not speak Dutch sufficiently. The 525 eligible persons made up the total group of spinal cord injured in the Netherlands in that period and of that age group, From this group, 423 persons were reached and 318 persons participated in the study. Based on information from medical files, there were no statistically significant differences at an alpha level of $1 \%$ between the response group and the non-response group with regard to type of SCI, cause of SCI, age, sex and time after injury. All respondents were interviewed at home, between March 1993 and May 1994.

\section{Instruments}

Type of injury was obtained by questioning respondents and checking this answer in medical files. We distinguished between cervical levels and lower levels, and between complete (Frankel Grades A or B) and incomplete (Frankel Grade C or D) injuries, so that in the analyses four categories of injuries are used: complete tetraplegic, incomplete tetraplegic, complete paraplegic and incomplete paraplegic.

Availability of services is based on information from respondents about (1) domestic adaptations: ramp to front door; removed tresholds; widening of doors; elevator to upper floor; adapted kitchen; toilet and bathroom; and an annex to the house, (2) wheelchairs; manual wheelchair; electrical wheelchair; other wheelchairs, and (3) outdoor transport: adapted car.

Satisfaction with available services is measured by a self-developed scale 'Satisfaction Services', that consists of two statements: 'I have all the adaptations and equiment I need', and 'My house is sufficiently adapted now'. Answers could be given on a fivepoint scale (full agreement to full disagreement). The total score on this scale ranges from one (very unsatisfied) to five (very satisfied).

Satisfaction with service delivery procedures is measured by a self-developed scale 'Satisfaction Procedures' that consists of four statements: 'I have had enough guidance in the course of service delivery procedures', I had to go after everything myself' 'In fact, I know more about my needs than professionals do', and I have received sufficient information about 
possible equipment and adaptations'. The scoring system of the answers was identical to the Satisfaction Services scale.

Functional health status is measured by the SIP68, a short version of the Sickness Impact Profile. ${ }^{15}$ The SIP68 contains 68 items, which are all statements regarding behaviour. Respondents were asked to check those items that both apply to their situation on the day they fill out the list and that are related to their health status. The items are distributed over six subscales. In this study, only the total SIP68-score is used. A higher score indicates worse functional health status. Reported reliability of the SIP68 is high, with a Cronbach's alpha of 0.92 and a test-retest reliability of 0.97 for the total score. ${ }^{16}$ In this study Chronbach's alpha of the total score is $0.92 .^{17}$

Life satisfaction is measured by the Life Satisfaction Questionnaire. ${ }^{18}$ The LSQ measures satisfaction with life in general and with eight specific domains (for example self-care, leisure situation, and family relations). LSQ item scores range from one (very dissatisfying) to six (very satisfying). The total LSQ score is obtained by summing up all nine item scores and dividing them by nine, so that the total LSQ score also has a possible range of 1 to 6 . In this study, Cronbach's alpha of the LSQ is 0.74 .

\section{Statistical procedures}

All analyses are performed with SPSS, version 5.01. Non-parametric methods were used as much as possible, including Chi-square, Spearman-Brown correlations, Mann-Whitney order-of-ranks test for differences between two groups and Kruskall-Wallis analyses of variance for differences between three or more groups. The predictive value of Satisfaction Services and Satisfaction Procedures for functional health status and for life satisfaction was analyzed using multiple regression analyses. With the 'Test'procedure, it was first examined whether the two satisfaction variables make a significant prediction of functional health status, after taking the type of injury (high/low and complete/incomplete) into account. After that, with the same procedure it is examined whether the two satisfaction variables make a significant additional prediction of life satisfaction, after taking the functional health status into account.

\section{Results}

In the response group, mean age was 39.4 years (SD $12.5)$. The majority were male $(75.4 \%)$ and $57.1 \%$ were married or living together. The types of SCI included $21.7 \%$ complete tetraplegia, $20.4 \%$ incomplete tetraplegia, 29.2\% complete paraplegia and 28.6\% incomplete paraplegia. The main causes of SCI in the response group were traffic accidents $(34.9 \%)$, followed by $15.1 \%$ sports accidents, $12.9 \%$ occupational accidents, $10.4 \%$ resulting from bodily processes, $9.1 \%$ falls, and $7.5 \%$ resulting from medical treatment. Time since injury was between 2 to 7 years (mean 3.6 years, SD 1.9). Most respondents $(60.0 \%)$ were wheelchair dependent.

\section{Domestic adaptations}

About half of all respondents $(50.6 \%)$ could stay in their homes despite the SCI (Table 1), and a further $24.2 \%$ moved to another regular house, so that threequarters of all respondents stayed in a regular house. The percentage of respondents that had to move is related to the type of the SCI: $71 \%$ of all complete tetraplegics had to move, against $54.8 \%$ of all complete paraplegics and against $36.5 \%$ of all incompletely injured.

Table 2 shows the percentage of respondents who got some common domestic adaptations (Table 2). These figures are restricted to the 238 respondents who stayed in their houses or moved to other regular houses, because in the other living situations all necessary adaptations were already available. Most widespread adaptations were the removing of thresholds, widening of doors and adaptations of the toilet or bathroom. Adaptations of the kitchen was also often done, especially when the spinal cord injured was a woman. Building an annex, which usually consisted of a bedroom and a bathroom with a toilet, was frequently done for persons with a complete SCI. When an annex was built, it replaced adaptations of the existing bedroom, toilet and bathroom. In that case, the upper floor of the house remained inaccessible.

Many respondents complained about the amount of time needed to adapt their houses. In fact, almost one third of our respondents $(n=110)$ said that their discharge from the rehabilitation centre was delayed by a median time of 15.5 weeks, because they had to wait for another house or for adaptation of their houses.

Only $10 \%$ of all respondents did not have any domestic adaptations at all, divided in $2.2 \%$ of complete tetraplegics and $2.2 \%$ of complete paraplegics, and $18.5 \%$ of incomplete tetraplegics and $18.7 \%$ of incomplete paraplegics (Chi-square 22.24, $P<0.001)$. The completely injured who did not have domestic adaptations at the time of the interview were

Table 1 Number of persons forced to move after SCI

\begin{tabular}{lrc}
\hline & $n$ & $\%$ \\
\hline Stayed in their homes & 161 & 50.6 \\
Moved to another regular house & 77 & 24.2 \\
Moved to a house build for disabled & 48 & 15.1 \\
Moved to 'FOCUS'-house or & 17 & 5.3 \\
'Woonvorm' & 15 & 4.7 \\
Other answers & 318 & 99.9 \\
Total
\end{tabular}

FOCUS-house or Woonvorm are comparable to independent living centres 
still waiting for another house or 'FOCUS'-house (at that moment more than a year after discharge), or did not need them at all.

\section{Lacking domestic adaptations}

Most respondents who had one or more domestic adaptations agreed or fully agreed with the statement 'My house is sufficiently adapted now' $(78.3 \%)$. But a substantial group $(38.1 \%)$ declared that they did not get all the domestic adaptations they requested, ranging from $28.1 \%$ of all incomplete paraplegics up to $49.3 \%$ of all complete tetraplegics (Chi-square 8.16, $P=0.043)$. An unknown number of respondents outside the $38.1 \%$ said that domestic adaptations had been denied, but that they had paid for these by themselves. Unavailable adaptations were the following (no. of respondents):

- Accessibility within the house (19). Nine of these concerned an elevator that was not assessed because bedroom and bathroom were on the ground floor so that there was no medical reason for the respondent to go to the upper floor of the house. Others indicated that their rooms were too small to manoeuver a wheelchair.

- Accessibility of the house (16). Nine of these were about electric doors, for instance when the front door had been adapted but the backdoor had not because it was considered to be not necessary.

- Kitchen adaptations (17). In some cases this adaptation was denied by the payor because the total costs would exceed 45,000 guilders. In most cases it was denied because there was no medical need assessed when, for instance, a spinal cord injured man lived with a healthy wife. Several electric or magnetic hot plates were denied because they were considered a luxury.

- Bathroom or toilet adaptations (14), for example making a bathtub better accessible.

- Adaptations outside the house (13), for example making a garage or a garden accessible.

- Other adaptations (12), for example an environmental control system for a complete tetraplegic.

- Not specified (28).

Respondents who felt their house was sufficiently adapted, had a mean score on Satisfaction Services of 4.3, against a mean score of 3.0 for the others. This group had a mean score on Satisfaction Procedures of 2.50 , against 2.07 for the others $(Z=4.16, P<0.001)$.

\section{Wheelchairs}

Of all respondents, $82.4 \%$ had one or more wheelchairs and $60.0 \%$ were completely wheelchair-dependent. Table 3 shows figures of wheelchair availability by type of injury. Almost all completely injured had a manual wheelchair. An electric wheelchair was common for complete tetraplegics. Respondents in the other groups sometimes had an electric wheelchair for outdoor transportation (like a Booster Trophy). The group 'other wheelchairs' included: sportwheelchairs, lightweight wheelchairs, or extra manual wheelchairs. Many complete tetraplegics were not able to use a manual wheelchair by themselves and might have it only as backup or to visit a place that is inaccessable with an electric wheelchair. This is also the explanation for the relatively low prevalence of other wheelchairs in this group.

Table 2 Availability of domestic adaptations in common houses by type of SCI $(n=238)$

\begin{tabular}{|c|c|c|c|c|c|}
\hline & $\begin{array}{l}\text { Complete } \\
\text { tetraplegia } \\
(\mathrm{n}=37)\end{array}$ & $\begin{array}{l}\text { Incomplete } \\
\text { tetraplegia } \\
\quad(\mathrm{n}=53)\end{array}$ & $\begin{array}{c}\text { Complete } \\
\text { paraplegia } \\
(\mathrm{n}=74)\end{array}$ & $\begin{array}{l}\text { Incomplete } \\
\text { paraplegia } \\
(\mathrm{n}=74)\end{array}$ & $\begin{array}{c}\text { Total } \\
(\mathrm{n}=238)\end{array}$ \\
\hline Ramp to front door & 46.0 & 24.5 & 43.2 & 32.4 & 36.1 \\
\hline Thresholds & 89.2 & 43.4 & 78.4 & 47.3 & 62.6 \\
\hline Doors & 78.4 & 28.3 & 67.6 & 32.4 & 49.6 \\
\hline Elevator & 27.0 & 17.0 & 23.0 & 16.2 & 20.2 \\
\hline Kitchen & 29.7 & 34.0 & 59.5 & 32.4 & 40.8 \\
\hline Toilet and bathroom & 83.8 & 58.5 & 83.8 & 62.2 & 71.4 \\
\hline Annex to the house & 43.2 & 13.2 & 35.1 & 9.5 & 23.5 \\
\hline
\end{tabular}

All figures are percentages, for example: of all complete tetraplegics, $29.7 \%$ has an adapted kitchen

Table 3 Availability of wheelchairs by type of injury $(n=318)$

\begin{tabular}{lcccc}
\hline & $\begin{array}{c}\text { Complete } \\
\text { tetraplegia } \\
(\mathrm{n}=69)\end{array}$ & $\begin{array}{c}\text { Incomplete } \\
\text { tetraplegia } \\
(\mathrm{n}=65)\end{array}$ & $\begin{array}{c}\text { Complete } \\
\text { paraplegia } \\
(\mathrm{n}=93)\end{array}$ & $\begin{array}{c}\text { Incomplete } \\
\text { paraplegia } \\
(\mathrm{n}=91)\end{array}$ \\
\hline Manual wheelchair & 94.2 & 61.5 & 98.9 & 65.9 \\
Electric wheelchair & 69.6 & 26.2 & 19.4 & 17.6 \\
Other wheelchair & 37.7 & 26.6 & 67.7 & 30.8 \\
\hline
\end{tabular}

All figures are percentages 
A minority of $17.3 \%$ did not have any wheelchair at all, all save one were incompletely injured and all indicated being able to walk. Of those who were fully wheelchair bound, $17.5 \%$ had one wheelchair, $70.9 \%$ had two wheelchairs and $11.6 \%$ had three or more wheelchairs. Of those who were able to walk (with or without difficulties), $43.7 \%$ had no wheelchair, $23.8 \%$ had one, $29.4 \%$ had two and $3.2 \%$ had three wheelchairs.

Many respondents had complaints about their wheelchairs: $35.9 \%$ regarding to manual wheelchairs, $47.5 \%$ regarding to electric wheelchairs and $35.6 \%$ regarding to other wheelchairs. It was not possible to detect systematic differences between brands or types of wheelchairs, every brand had users who said it was too heavy, too vulnerable, badly manoeuverable or that it was simply too ugly ('You look like an idiot in that thing'). With regard to electric wheelchairs, further complaints concerned electronical problems, low maximum speed and their size, especially their width that makes it impossible to enter, for example, many shops and houses of friends.

There were no significant differences between wheelchair-users with different types of injuries regarding to manual wheelchairs or other wheelchairs. With regard to electric wheelchairs, complete tetraplegics complained considerably more often about their wheelchairs $(66.7 \%)$ than users in the other three groups (about 30\%, Chi-square 13.81, $P=0.003$ ).

Respondents who had no complaints about their wheelchairs $(n=166)$ had a mean score on Satisfaction Services of 4.0 against 3.6 for the others $(n=141)$ $(\mathrm{Z}=3.97, \quad P<0.001)$, and had a mean score on Satisfaction Procedures of 2.4 against 2.2 for the others $(Z=2.37, P=0.018)$.

\section{Outdoor transport}

Public transport was only rarely used: $15.1 \%$ took a train sometimes or regularly, and only $7.2 \%$ took a bus sometimes or regularly. A taxi was used more often; a wheelchair-taxi was used sometimes or regularly by $29.6 \%$, and a common taxi was used sometimes or regularly by $33.3 \%$.

Most respondents $(51.1 \%)$ had an adapted car and were able to drive independently $(61.3 \%)$. Some respondents did not need an adapted car and others were not able to drive independently with an adapted car. Table 4 shows that, regardless of the type of the injury, having an adapted car was related to more independence in driving. $31.8 \%$ of all respondents reported having transportation problems; $42.2 \%$ of those without an adapted car and $22.2 \%$ of those with an adapted car (Chi square $=14.97 ; \mathrm{Df}=1 ; P<0.001)$. A few completely injured respondents stated that they were able to drive without having an adapted car. This might be explained by, for example, that these respondents know that they are able to drive an adapted car but do not have none by themselves.

Respondents with an adapted car $(n=164)$ had a mean score on Satisfaction Services of 4.0 against 3.6 for the others $(n=143)(Z=2.89, P=0.004)$, and had a mean score on Satisfaction Procedures of 2.6 against 2.1 for the others $(Z=4.68, P<0.001)$.

\section{Satisfaction with available services}

General satisfaction with available services had a mean score of 3.8 (s.d. $=1.20$ ) and $45 \%$ of respondents gave a maximum or nearly maximum score (4.5 or 5.0$)$. Satisfaction Services is not significantly related to type of injury, age, education, or income.

\section{Satisfaction with service delivery procedures}

In general, satisfaction with service delivery procedures was low. The mean score on Satisfaction Procedures was $2.3(\mathrm{SD}=0.89)$. Satisfaction Procedures is not significantly related to age, education, or income, but completely injured tend to be less satisfied with service delivery procedures than incompletely injured $(\mathrm{K}-\mathrm{W}$ anova, Chi-Square $=14.47, P=0.002$ ).

A majority of respondents $(57.6 \%)$ indicated they had problems with obtaining their wheelchairs. Almost half of all respondents $(48.6 \%)$ indicated that a request for a particular service had been denied, although most respondents got what they wanted in the end (whether or not by paying for it themselves). The answers on the statements regarding different aspects of service delivery procedures are presented in Table 5.

On all four statements, a majority of respondents choose a negative answer. It is remarkable how many respondents were of the opinion that, with regard to

Table 4 Percentage of respondents able to drive independently by availability of an adapted car and by type of injury

\begin{tabular}{lccccc}
\hline & $\begin{array}{c}\text { Complete } \\
\text { tetraplegia } \\
(\mathrm{n}=69)\end{array}$ & $\begin{array}{c}\text { Incomplete } \\
\text { tetraplegia } \\
(\mathrm{n}=65)\end{array}$ & $\begin{array}{c}\text { Complete } \\
\text { paraplegia } \\
(\mathrm{n}=93)\end{array}$ & $\begin{array}{c}\text { Incomplete } \\
\text { paraplegia } \\
(\mathrm{n}=91)\end{array}$ & $\begin{array}{c}\text { Total } \\
(\mathrm{n}=318)\end{array}$ \\
\hline Adapted car available $(\mathrm{n}=167)$ & 41.0 & 91.3 & 96.7 & 95.5 & 82.6 \\
No adapted car available $(\mathrm{n}=151)$ & 13.3 & 35.7 & 25.0 & 63.8 & 37.8 \\
Total $(\mathrm{n}=318)$ & 29.0 & 55.4 & 72.0 & 79.1 & 61.3 \\
\hline
\end{tabular}

All figures are percentages; for example: out of all respondents with complete tetraplegia, $41.0 \%$ of those with an adapted car are able to drive independently, and $13.3 \%$ of those without an adapted car are able to drive independently 
Table 5 Satisfaction with service delivery procedures

\begin{tabular}{lcc}
\hline & $\begin{array}{c}\text { Fully agree }+ \\
\text { agree }\end{array}$ & $\begin{array}{c}\text { Disagree }+ \\
\text { fully disagree }\end{array}$ \\
\hline $\begin{array}{l}\text { I had enough support in the course of } \\
\text { the procedures }\end{array}$ & 32.4 & 10.5 \\
$\begin{array}{l}\text { I had to go after everything by myself } \\
\text { In fact, you know better what you need by } \\
\quad \text { yourself, than the professionals do }\end{array}$ & 68.6 & 11.1 \\
$\begin{array}{l}\text { I got enough information about possible } \\
\text { equipment and adaptations }\end{array}$ & 76.5 & 12.3 \\
\hline
\end{tabular}

All figures are percentages

their own needs, they were more capable than the professionals were. Many respondents complained about the way they were treated (especially by GMD-professionals), the number of organisations and officials involved, and the amount of time required by these procedures.

\section{Satisfaction with service delivery and functional health status}

The bivariate correlations of Satisfaction Services and Satisfaction Procedures with the SIP68 are -0.25 $(P<0.001)$ and -0.09 (NS) respectively, indicating that satisfaction with available services is related to better functional health status. This relationship might be explained by differences in seriousness of the injury, and therefore a multiple regression analysis was used. As a result, the variables level and completeness of lesion together explained $27 \%$ of the variance of the SIP68-score $(\mathrm{F}=52.06, P<0.001)$. Satisfaction Services explained an additional $2.4 \%(\mathrm{~F}=10.03, P=0.002)$. A second analysis with Satisfaction Procedures as the dependent variable did not show a significant relationship.

Satisfaction with service delivery and life satisfaction The bivariate correlations of Satisfaction Services and Satisfaction Procedures with the LSQ are 0.32 $(P<0.001)$ and $0.11(\mathrm{NS})$ respectively, indicating that satisfaction with available services is related to higher life satisfaction. A multiple regression analysis showed that the SIP68-score explained $29 \%$ of the LSQ-score variance $(F=115.82, P<0.001)$. Service Satisfaction explained an additional 5.0\% $(\mathrm{F}=22.03, P<0.001)$, and Satisfaction Procedures again did not make a difference with regard to the prediction of the LSQ-score.

\section{Discussion}

This article discusses the service delivery for spinal cord injured people in the Netherlands. The presence of domestic adaptations in this study is high compared to the study of Harvey et $a l^{19}$ who found that $60.2 \%$ of all spinal cord injured, and $82.0 \%$ of complete tetraplegics, had one or more home modifications.
However, a comparable number of respondents, $23.0 \%$ or $54.5 \%$ of complete tetraplegics, built additional rooms or new houses. Our figures are also comparable to those of Nakajima et $a l^{20}$ regarding Japan, where nearly the same percentage of respondents $(87 \%)$ altered their houses and somewhat more respondents $(43 \%)$ extended their houses.

Most respondents were able to stay in their houses after the injury. Other studies do not present figures about moving to other houses. The Netherlands are deficient in adapted houses, so the percentage of respondents who had to move could have been higher if more already adapted houses had been available.

In our study, satisfaction with domestic adaptations was acceptable, with nearly $80 \%$ of all respondents indicating that their houses were sufficiently adapted, but also with a substantial group of respondents $(38 \%)$ who said that they were lacking one or more adaptations. In the literature, there are few other figures available. Welch ${ }^{21}$ mentions that in his small group of 29 tetraplegics a comparable $69 \%$ rated their houses as fully accessible. Harrison found a percentage of $54 \%$ positive answers on this question, in a study with a very low response rate $(28 \%)$. Our figure is nearly the same as the $40 \%$ that Whiteneck ${ }^{9}$ found in 282 SCI, but the latter percentage covers all sorts of equipment. Further research on this topic is necessary.

In our study, nearly everyone who needed a wheelchair also got one, and usually had several wheelchairs. In the US, second wheelchairs are commonly denied, ${ }^{22}$ so that a comparison is not applicable at this point. A small study SCI Individuals in Denmark ${ }^{23}$ found comparable results, out of 41 with a paraplegia $(27 \%$ incomplete) $85 \%$ had a manual wheelchair and $5 \%$ had an electric wheelchair, and out of 17 with a tetraplegia (29\% incomplete) these figures were $94 \%$ and $53 \%$ respectively.

Other research regarding satisfaction with available wheelchairs does not seem to be available. We found that a substantial portion of the respondents had complaints about one or more of their wheelchairs. Unfortunately, a more detailed description with an arrangement of complaints in levels of seriousness from the user or from a professional point of view is not available. So far, this finding also stresses the need for further research. 
Regarding availability of adapted cars and transportation problems, more published results are available. In the Danish study of Drewes, ${ }^{23} 81 \%$ of those with paraplegia and $78 \%$ with tetraplegia had an adapted car. In Germany, Wahle ${ }^{24}$ found that 10 years after injury, $82.2 \%$ of 50 with complete paraplegia could drive a car, which was only $20 \%$ at discharge. In the study of Nakajima, ${ }^{20} 15 \%$ of all tetraplegic patients and $58 \%$ of all those with paraplegia were able to drive a car. In the US, Welch found that of complete C7-injured, all who could afford the financial requirement, could drive independently. According to Harrison, ${ }^{7}$ only $27 \%$ of 62 SCI had their own car or van and could drive independently. He also noted that the lack of financial resources had a large impact on their access to transportation. Our research highlights the importance of outdoor transport for spinal cord injured.

As far as we know, our study is the first that presents figures about satisfaction with service delivery procedures. Satisfaction with these procedures was very low, even though most respondents got what they wanted in the end. Apart from the treatment, the slowness of procedures caused the most dissatisfaction. Almost one third of our respondents said their discharge from the rehabilitation centre was delayed by 15.5 weeks (median time) because they had to wait for another house or for adaptations to their house. These results add to those of Forrest and Gombas ${ }^{25}$ and support their conclusion that the availability of accessible housing influences the length of stay in a rehabilitation centre.

Satisfaction with available services was significantly related to functional health status and to life satisfaction. This finding does not result from a generally felt gloominess, because the obvious dissatisfaction with service delivery procedures did not have any relationship with either functional health status or life satisfaction.

In the Netherlands, almost everyone has access to domestic adaptations and other adaptive equipment, regardless of income and with or without low user contributions. According to LaPlante, ${ }^{26}$ in the US about half of the persons with assistive technology and more than three-fourths of the persons with home accessibility features, purchased them themselves or with the help of their families without contribution from third-party payers. More than 2.5 million Americans said they need assistive technology devices that they do not have, mostly (three-fifths) because they cannot afford them. It is likely that a replication of this study in another country shall reveal even less encouraging results, an expectation that of course emphasizes its necessity.

\section{Acknowledgements}

This research is funded by a grant from the Utrecht University.

\section{References}

1 Sipski ML, Hendler S, DeLisa JA. Rehabilitation of patients with spinal cord disease. Neurol Clinics 1991; 9: 705-725.

2 O'Day BL, Corcoran PJ. Assistive technology: problems and policy alternatives. Arch Phys Med Rehabil 1994; 75: 1165-1169.

3 Gerhart KA. Changing the adaptive environment. In: Whiteneck et al (ed). Aging with spinal cord injury, Demos publications: New York 1993

4 Tate DG et al. The effect of insurance benefits coverage on functional and psychosocial outcomes after spinal cord injury. Arch Phys Med Rehabil 1994; 75: 407-414.

5 Asbeck FWA van, Raadsen H, Loo MLJJ van de. Social implications for persons 5-10 years after spinal cord injury. Paraplegia 1994; 32: 330-335.

6 Asbeck FWA van. Functioneren met een paraplegie. $\mathrm{PhD}$ Thesis R.U. Groningen: Groningen, 1987.

7 Harrison C, Kuric J. Community reintegration of spinal cord injured persons: problems and perceptions. Sci Nurs 1989; 6: $44-$ 47.

8 Nelson et al. Descriptive study of bowel care practices and equipment in spinal cord injury. SCI Nurs 1993; 10: 65-67.

9 Whiteneck GG et al. Mortality, morbidity, and psychosocial outcomes of persons spinal cord injured more than 20 years ago. Paraplegia 1992; 32: 617-630.

10 Shirado O, Shundo M, Kaneda K, Strax TE. Outdoor winter activities of spinal cord-injured patients with special reference to outdoor mobility. Am J Phys Med Rehabil 1995; 74: 408 - 414.

11 Brooks NA. Users' responses to assistive devices for physical disability. Soc Sci Med 1991; 32: 1417-1424.

12 Witte L de, Knops H, Pyfers L, Röen P. European service delivery systems in rehabilitation technology (HEART line C). IRV: Hoensbroek, 1994.

13 Schoemakers-Salkinoja I, Hessing Wagner J. Samenhang in de zorg voor lichamelijk gehandiapten. Sociaal Cultureel Planbureau: Rijswijk, 1987.

14 Bougie ThHM. Handicap en technologie. Handboek Handicap en Chronische Ziekte. De Tijdstrooom: Utrecht 1995, pp XI-1-1 to XI-1-31.

15 Bruin AF de et al. The development of a short generic version of the sickness impact profile. J Clin Epidemiol 1994; 47: 407-418.

16 Bruin AF de, Witte LP de, Diederiks JPM. The Sickness Impact Profile: SIP68 a short generic version: first evaluation of the reliability and reproducibility. J Clin Epidem 1994; 74: 863 -871.

17 Post MWM, Bruin AF de, Witte L de, Schrijvers G. The SIP68: a measure of health related functional status in rehabilitation medicine. Arch Phys Med Rehabil 1996; 77: 440-445.

18 Fugl-Meyer AR, Bränholm I-B, Fugl-Meyer KS. Happiness and domain-specific life satisfaction Clin Rehabil, 1991; 5: 25-33.

19 Harvey C et al. New estimates of the direct costs of traumatic spinal cord injuries: results of a nationwide survey. Paraplegia 1992; 30: $834-850$

20 Nakajima A, Honda S. Physical and social condition of rehabilitated spinal cord injury patients in Japan: a long term review. Paraplegia 1988; 26: 165-176.

21 Welch RD, Lobley SJ, O'Sullivan SB, Freed MM. Functional independence in quadriplegia: Critical levels. Arch Phys Med Rehabil 1986; 67: $235-240$.

22 Donovan WH, Carter RE, Wilkerson MA. Profile of denials of durable medical equipment for SCI patients by third party payers. Am J Phys Med Rehabil 1987; 66: 238 - 243.

23 Drewes AM, Olsson AT, Slot O, Andreasen A. Rehabilitation outcome for patients with spinal cord injury. Int Disab Studies 1990; 11: $178-180$.

24 Wahle H. 10-Jahres-katamnese zum poststationären trainingsstand bei 50 patienten mit kompletter paraplegie. Rehabilitation 1991; 30: 3-13.

25 Forrest G, Gombas G. Wheelchair-accessible housing: its role in cost containment in spinal cord injury. Arch Phys Med Rehabil 1995; 76: $450-452$.

26 LaPlante MP, Hendershot GE, Moss AJ. Assistive technology devices and home accessibility features: prevalence, payment, need and trends. Advance Data nr 217, 1992. 